\title{
Impacts of climate and catastrophic forest changes on streamflow and water balance in a mountainous headwater stream in Southern Alberta
}

\author{
V. Mahat ${ }^{1}$ and A. Anderson ${ }^{1,2}$ \\ ${ }^{1}$ Department of Renewable Resources, University of Alberta Edmonton, AB T6G 2H1, Canada \\ ${ }^{2}$ Water Program Lead, Foothills Research Institute P.O. Box 6330 Hinton, AB T7V 1X6, Canada \\ Correspondence to: V. Mahat (mahat@ rams.colostate.edu) and A. Anderson (aanderson@ foothillsri.ca)
}

Received: 14 June 2013 - Published in Hydrol. Earth Syst. Sci. Discuss.: 2 July 2013

Revised: 17 October 2013 - Accepted: 30 October 2013 - Published: 9 December 2013

\begin{abstract}
Rivers in Southern Alberta are vulnerable to climate change because much of the river water originates as snow in the eastern slopes of the Rocky Mountains. Changes in likelihood of forest disturbance (wildfire, insects, logging, etc.) may also have impacts that are compounded by climate change. This study evaluates the impacts of climate and forest changes on streamflow in the upper parts of the Oldman River in Southern Alberta using a conceptual hydrological model, HBV-EC (Hydrologiska Byråns attenbalansavdelning, Environment Canada), in combination with a stochastic weather generator (LARS-WG) driven by GCM (global climate model) output climate data. Three climate change scenarios (A1B, A2 and B1) are selected to cover the range of possible future climate conditions (2020s, 2050s, and 2080s). The GCM projected less than a $10 \%$ increase in precipitation in winter and a similar amount of precipitation decrease in summer. These changes in projected precipitation resulted in up to a $200 \%(9.3 \mathrm{~mm})$ increase in winter streamflow in February and up to a $63 \%(31.2 \mathrm{~mm})$ decrease in summer flow in June. Flow also decreased in July and August, when irrigation is important; these reduced river flows during this season could impact agriculture production. The amplification in the streamflow is mostly driven by the projected increase in temperature that is predicted to melt winter snow earlier, resulting in lower water availability during the summer. Uncertainty analysis was completed using a guided GLUE (generalized likelihood uncertainty estimation) approach to obtain the best 100 parameter sets and associated ranges of streamflows. The impacts of uncertainty in streamflows were higher in spring and summer than in winter
\end{abstract}

and fall. Forest change compounded the climate change impact by increasing the winter flow; however, it did not reduce the summer flow.

\section{Introduction}

The eastern slopes of the Rocky Mountains in Alberta, Canada, have the highest precipitation and runoff ratios (annual streamflow as a proportion of annual precipitation). This generates the majority of streamflow for many rivers including the Oldman River, which provides water for domestic and recreational purposes and supports a broad base of regional agriculture and fishery industries in Southern Alberta (Bladon et al., 2008; Emelko et al., 2011; Silins et al., 2009; Stone et al., 2001). Hydrology of mountainous regions are most likely to be affected by climate change as precipitation would change from snow to rain in a warming climate (IPCC, 2007). Headwater streams and rivers supporting the Oldman River system originate as snow in the eastern slopes of the Rocky Mountain and are vulnerable to a warming climate. Forest change may compound the impacts of climate change. Given the present near-full allocation of water for human use in this region, along with the possibility of longer-term limitations in water supply, understanding and predicting how climate and forest changes in this region are likely to affect the production/timing of streamflow are increasingly important (Silins et al., 2009).

There have been a number of studies that have delved into the potential effects of climate change on hydrology and 
water resources in many regions. Apparent trends in streamflow due to climate change are both increasing and decreasing (Arnell, 1999; Zheng et al., 2009). Arnell (1999) investigated the climate change impacts on water supply on the global scale and reported up to a $15 \%$ decrease in streamflow in major river basins by the year 2050. Studies carried out in different regions (i.e., Jha et al. (2004; Upper Mississippi River basin, USA), Stone et al. (2001; Missouri River basin, USA), Hamlet and Lettenmaier (1999; Columbia River basin, USA), Kienzle et al. (2012; North Saskatchewan River basin, AB, Canada), Stahl et al. (2008; Bridge River basin, BC, Canada), Forbes et al. (2011; Beaver Creek watershed, Canada) and Kalogeropoulos and Chalkias (2013; small catchment in Greece)) have reported a streamflow increase of up to $80 \%$ in fall and winter and a $10 \%$ to $20 \%$ decrease in summer. Barnett et al. (2005) studied a number of large basins around the globe and reported streamflow regime in snowmelt-dominated river basins is the most sensitive. As melting of winter snow occurs earlier in spring due to temperature rise, there is likely to be future water scarcity in the snowmelt-dominated regions during the summer. Other studies (e.g., Barnett et al., 2008; Hidalgo et al., 2009; Mote, 2003; Pierce et al., 2008) that are focused on the snowmeltdominated regions have also reported a reduction in snow and an early shift in the timing of the streamflow.

GCMs (general circulation models or global climate models) are widely used to project future climates under assumed greenhouse gas emission scenarios, both in space and time (e.g., IPCC, 2007; Mehrotra and Sharma, 2010). However, the projections from these models are typically provided at coarse resolutions, i.e., $200 \mathrm{~km}$ or more, in space and monthly time periods (Wang et al., 2012). The hydrologic processes of interest normally occur at scales on the order of tens to thousands of square kilometers; so the resulting climate projections from GCMs cannot be directly used as input for models at the resolution of interest to hydrologists (Epstein and Ramírez, 1994; Morrison et al., 2002). Consequently, various downscaling techniques that include stochastic, statistical, or dynamic downscaling (Fowler et al., 2007; Maurer et al., 2009; Wang et al., 2012) have been developed to derive higher-resolution climate data from the coarser-resolution climate projections. Dynamic downscaling refers to the use of regional climate models (RCMs) (Fowler et al., 2007; Mehrotra and Sharma, 2010). Catchment scale hydrological climate change impact studies have used dynamically downscaled output (e.g., Fowler and Kilsby, 2007; Wood et al., 2004), simple statistical approaches such as multiple regression relationships (e.g., Jasper et al., 2004; Wilby et al., 2000), and stochastic weather generator (e.g., Evans and Schreider, 2002).

Potential impacts of future climate change on hydrology have been assessed through the application of hydrological models driven by the downscaled GCM-derived future climates (Campbell et al., 2011; Forbes et al., 2011; Kienzle et al., 2012; Loukas et al., 2002; Toth et al., 2006). A detailed, physically based model could be an effective tool; however, applying a detailed model requires large numbers of input forcing which are seldom available, especially in mountain region studies. So, the selection of the model may depend on the availability of data for the study region.

The purpose of this study is to evaluate the plausible worstcase scenario of changes to the hydrology at larger scales following a large catastrophic forest change (such as wildfire) under present and possible future climates by simulating the removal of forest. We focus on the southern portions of high-water-yielding headwaters of Alberta's eastern slopes that supply the overwhelming majority of usable surface water for communities. These mountain regions are more susceptible to future temperature change as a large proportion of the precipitation falling in these regions is snow which will partly change to rain in a warming climate, thereby affecting the timing and magnitude of streamflow (Forbes et al., 2011; Kienzle et al., 2012).

\section{Study watershed and data}

The Crowsnest Creek watershed (Fig. 1), centered at $49.64^{\circ} \mathrm{N}, 114.55^{\circ} \mathrm{W}$, is an important watershed in Southern Alberta, Canada. It feeds the Oldman River which is closed to the issuing of new water extraction licenses due to a growing imbalance between demand and supply (Emelko et al., 2011). This watershed has a drainage area of $384 \mathrm{~km}^{2}$ with the elevation ranging from 1236 to $2732 \mathrm{~m}$. The watershed is broadly characteristic of Rocky Mountain front-range physiographic settings. Vegetation in the watershed is characterized by Lodgepole pine (Pinus contorta Dougl. ex Loud. var. latifolia Engelm.)-dominated forest at lower elevations, subalpine forest at mid-elevations dominated by Engelmann spruce (Picea engelmannii Parry ex Englem.) and subalpine fir (Abies lasiocarpa (Hook.) Nutt.) with alpine ecozones at higher elevations characterized by alpine meadow vegetation and bare rock extending above tree line (Silins et al., 2009).

Weather in this region is dominated by maritime polar air mass from the North Pacific and continental polar air mass mostly from Canada's interior and occasionally from the Arctic. Air masses from the North Pacific and Canada's interior interact with cold and warm fronts to produce daily precipitation, while intense cold weather is generated when the Arctic air mass interacts with these fronts. The majority of the total annual precipitation (50\% to $70 \%$ ) in these catchments falls as snow from October to April. Streamflows in the study area are characteristic of very high water yielding Rocky Mountain streams. Spring snowmelt generally produces the highest continuous streamflows. Rain-on-snow or mid-winter melt events are a common occurrence, producing some of the larger flows, with mean daily discharge in excess of $30 \mathrm{~mm} \mathrm{day}^{-1}$. The late summer and over-winter period are generally near $0.5-2 \mathrm{~mm} \mathrm{day}^{-1}$ (Silins et al., 2009). Hydrology of all these catchments are snowmelt dominated and 


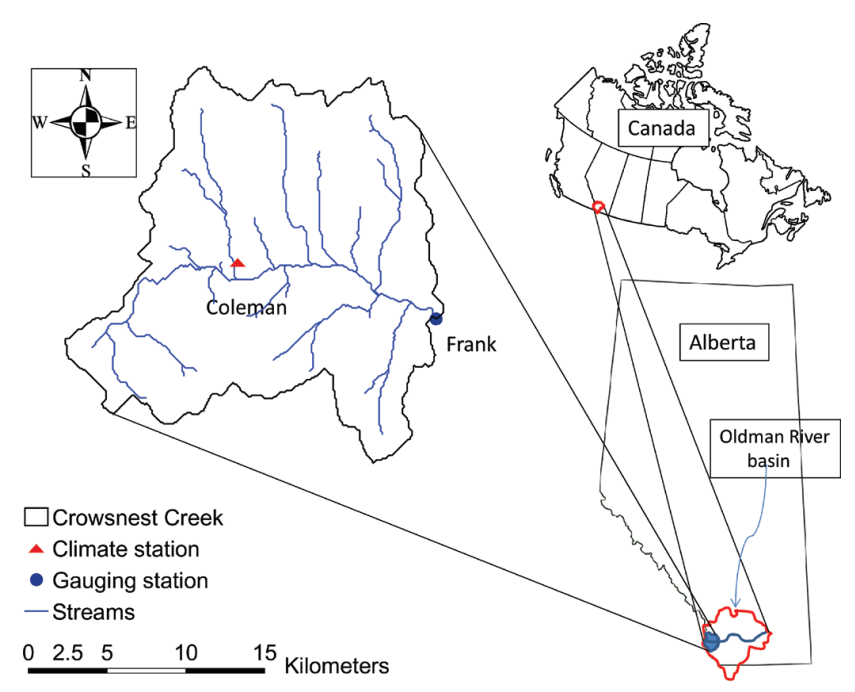

Fig. 1. Crowsnest Creek watershed with climate station, Coleman, and gauging station, Crowsnest at Frank.

peak flows are driven by spring snowmelt or rain on spring snowmelt.

Climate has been monitored continuously by seven climate stations within this watershed by Environment Canada (http: //climate.weatheroffice.gc.ca/climateData/canada_e.html).

However, a long record of daily climate data (i.e., about $32 \mathrm{yr}$, from 1965 to 1997) is available only at Coleman climate station which lies at the approximate center of the watershed (Fig. 1). We use climate data recorded at this station to drive the daily climatological condition across the entire watershed, herein called the Coleman climate station. Long-term mean annual precipitation and mean daily temperature recorded at this station are about $600 \mathrm{~mm}$ and $3.5^{\circ} \mathrm{C}$, respectively. Streamflow data used in this study are the daily data recorded at the gauging station on the Crowsnet River at Frank (Hydat Station: 05AA008), located close to the city of Blairmore, $\mathrm{AB}$. This station is well suited for the analysis as long-term records of streamflow data, which are necessary for calibrating and validating the model that simulates the effect of climate change on streamflow, are available at this station. Long-term mean annual streamflow recorded at this station is about $400 \mathrm{~mm}$.

\section{Methodology}

The study methodology to assess the climate change impacts on streamflow involves three steps:

- Estimation of future monthly climate means (precipitation; maximum temperature, $T_{\max }$; and minimum temperature, $T_{\min }$ ) in relation to observed (reference) climates at the Coleman climate station;
- Weather generation and disaggregation (temporal downscaling) of monthly climate means into daily realizations for use with the hydrological model; and

- Hydrological model calibration, application and parameter uncertainty.

\subsection{Estimates of future monthly climate means}

\subsubsection{Climate model outputs and downscaling}

Projected climates used in this study are GCM outputs of $3.75^{\circ}$ latitude and $3.75^{\circ}$ longitude (approximately $339 \mathrm{~km}$ ) monthly climate means that are downscaled to $1 \times 1 \mathrm{~km}$ grids using the ClimateWNA model (Wang et al., 2006, 2012). The GCM used is the Canadian Climate Centre's Modelling and Analysis (CCCma) third-generation coupled global climate model (CGCM3) (http://www.ec.gc.ca/ccmac-cccma/ default.asp?lang=En $\backslash \& n=4$ A642EDE-1). ClimateWNA uses a combination of bilinear interpolation and elevation adjustment to downscale the climate data. To estimate the climate of any point of interest with known elevation, ClimateWNA extracts the monthly climates (precipitation and temperature) and elevation of four grid cells that are close to the point of interest. Climate and elevation of these four grids are bilinearly interpolated to give the climates and elevation of that point of interest. Following this, an elevation difference between the interpolated and the actual elevation from measurement (digital elevation model, DEM) is calculated and a lapse-rate-based elevation adjustment is applied on the interpolated climates. Lapse rate is derived from interpolated baseline (reference) climate surface.

\subsubsection{Changes in monthly climate means}

Downscaled $1 \times 1 \mathrm{~km}$ grids from within the study watershed boundary are averaged to estimate the watershed averaged monthly climate means for reference and future periods, and changes in monthly climate means (i.e., change in monthly mean daily maximum temperature, $\Delta T_{\max }$; change in monthly mean daily minimum temperature, $\Delta T_{\min }$; and change in monthly precipitation, $\Delta P$ ) are calculated as

$$
\begin{aligned}
& \Delta T_{\max }=\left(T_{\max }^{\mathrm{F}}+\varepsilon\right)-\left(T_{\max }^{\mathrm{R}}+\varepsilon\right), \\
& \Delta T_{\min }=\left(T_{\min }^{\mathrm{F}}+\varepsilon\right)-\left(T_{\min }^{\mathrm{R}}+\varepsilon\right), \\
& \Delta P=\frac{\varepsilon P^{\mathrm{F}}}{\varepsilon P^{\mathrm{R}}},
\end{aligned}
$$

where, $T_{\max }^{\mathrm{R}}, T_{\min }^{\mathrm{R}}$ and $P^{\mathrm{R}}$ are watershed averaged monthly mean daily maximum temperature, monthly mean daily minimum temperature and monthly precipitation, respectively, for the reference period, and $T_{\max }^{\mathrm{F}}, T_{\min }^{\mathrm{F}}$ and $P^{\mathrm{F}}$ are watershed averaged monthly mean daily maximum temperature, monthly mean daily minimum temperature and monthly precipitation, respectively, for the future period. $\varepsilon$ is the bias. 


\subsubsection{Future monthly climate means}

The reference period used in this study is between 1965 and 1997, chosen because of the observed daily climates available for the hydrological model calibration and validation during this period. Future periods selected are anomalies for $30 \mathrm{yr}$ normal periods 2011-2040 (2020s), 2041-2070 (2050s), and 2071-2100 (2080s). Three emission scenarios (A1B, A2, and B1) that were developed utilizing the Intergovernmental Panel on Climate Change (IPCC) Fourth Assessment Report, AR4, are used. The A1B scenario describes "a future world of very rapid economic growth, global population that peaks in mid-century and declines thereafter, and rapid introduction of new and more efficient technologies". The A2 scenario description is that "economic development is primarily regionally oriented and per capita economic growth and technological change are more fragmented and slower compared to A1B and B1 scenarios"; and the B1 scenario describes "a convergent world with the same global population that peaks in mid-century and declines thereafter, as in the A1 storyline, but with rapid changes in economic structures toward a service and information economy, with reductions in material intensity, and the introduction of clean and resource-efficient technologies" (IPCC, 2007).

Relative changes in monthly climate means at the Coleman climate station are assumed to be equivalent to the changes in watershed averaged monthly climate means, $\Delta T_{\max }, \Delta T_{\min }$ and $\Delta P$ that are obtained from Eqs. (1)(3). Daily observed climate at Coleman is aggregated to a monthly scale to give reference condition Coleman climate means $\left(T_{\max }^{\mathrm{R}}, T_{\min }^{\mathrm{R}}\right.$ and $\left.P^{\mathrm{R}}\right)$, and future monthly climate means at the Coleman climate station $\left(T_{\max }^{\mathrm{F}}, T_{\min }^{\mathrm{F}}\right.$ and $\left.P^{\mathrm{F}}\right)$ are calculated by reverting Eqs. (1)-(3).

\subsection{Weather generation}

\subsubsection{Weather generators}

A weather generator can be used to disaggregate monthly climate means into daily realizations for use with a hydrological model (Richardson and Wright, 1984). Weather generators are stochastic numeric models that simulate daily weather data at a single site using the separate statistical properties for each month's observed daily weather data for the given site (Racsko et al., 1991; Richardson et al., 1998; Semenov and Brooks, 1999). There are two types of daily weather generators used to determine wet or dry days and precipitation amount. Wet days are days with precipitation larger than zero. The first type, the Markov chain approach, uses a two-state first-order Markov chain to generate wet or dry days using a random process conditional upon the state of the previous day (Hughes et al., 1999). If a day is determined as wet, then the precipitation amount is computed using two-parameter gamma distribution. The second type, spell-length approach, generates wet or dry series. The length of each series is chosen randomly from the wet and dry semiempirical distribution for the month in which the series starts (Racsko et al., 1991; Wilks, 2012). The wet day precipitation value is generated using a semi-empirical precipitation distribution independent of the length of the wet series or the amount of precipitation on previous days (Semenov and Brooks, 1999).

\subsubsection{Disaggregation}

We use the Long Ashton Research Station Weather Generator (LARS-WG), which uses a more flexible semi-empirical approach compared to the Markov chain approach, which uses a simple standard distribution to generate a series of wet and dry days. In LARS-WG, daily $T_{\max }$ and $T_{\min }$ are modeled separately as stochastic processes with daily means and standard deviation conditioned on the wet or dry status of the day (Semenov and Brooks, 1999). The seasonal cycles of means and standard deviations are modeled by finite Fourier series of order 3 which is constructed using observed mean values, sine and cosine curve and phase angle for each month. LARS-WG also uses autocorrelation values for $T_{\min }$ and $T_{\max }$ derived from observed weather data to model the temperature. LARS-WG is available to the broader climate change impact study community via the Environment Canada website (http://www.cccsn.ec.gc.ca/index.php? page $=$ lars-wg).

Monthly statistical parameters of climates observed at the Coleman climate station are extracted using LARS-WG, and a new set of daily climates for the reference period 19651997 are generated. These generated climates are compared with the observed climates at the Coleman climate station to evaluate the performance of LARS-WG. Once reference climates are generated and validated, nine sets (for three different scenarios: A1B, A2 and B1; and for three different time periods: 2020s, 2050s and 2080s) of future periods' daily climates are generated disaggregating the future monthly climate means estimated for Coleman station. Although observed daily climates are available for the reference period, we use stochastically generated climates to provide input to the hydrological model to simulate the reference period streamflow. This makes the reference and future period streamflows comparable because they are generated with the same methods, and reflect the statistical properties of the climate periods.

\subsection{Hydrological model calibration, application and parameter uncertainty}

\subsubsection{HBV-EC}

A common conceptual hydrological model, HBV-EC, is used to study the hydrological impacts of climate change. HBV-EC is a version of the conceptual HBV model (Bergstrom and Forsman, 1973; Lindström et al., 1997); we 
chose HBV-EC because it is simple, easy to use and requires only daily/hourly precipitation and temperature, and monthly estimates of evapotranspiration as input to simulate daily/hourly discharge. The model is based on the concept of grouped response units (GRUs) that groups together DEM/GIS grid cells having similar elevation, aspect, slope and land cover. HBV-EC uses elevation bands subdivided into different land types (open, forest, glacier and water), slopes and aspects. Lateral climate gradients in HBV$\mathrm{EC}$ are represented by subdividing the basin into different climate zones; each of which is associated with a climate station and a unique set of parameters (Jost et al., 2012). The model consists of three main modules: (1) a snow module that simulates snow accumulation and melt using a degree-day approach; (2) a soil module that simulates groundwater recharge and actual evaporation as functions of soil moisture; and (3) a runoff transfer module that consists of one upper nonlinear reservoir representing fast responses and one lower linear reservoir representing slow responses to delay the runoff in time. Detailed descriptions of HBV-EC are given by Hamilton et al. (2000). HBV-EC is open source, available at the modeling framework "Green Kenue" (http://www.nrc-cnrc.gc.ca/eng/solutions/advisory/ green_kenue/download_green_kenue.html) developed by the National Research Council Canada in collaboration with Environment Canada.

\subsubsection{Hydrological model calibration}

HBV-EC model is driven by the $32 \mathrm{yr}(1965-1997)$ of daily climate data recorded at the Coleman climate station to simulate the streamflow, which is compared with observed flow at Frank for the calibration. The study watershed is divided into five different elevation zones, which are further divided into different land use types, slope and aspects. Land use of the study watershed consists of $92 \%$ combined forest types, $12 \%$ open area that includes bare rocks and the meadow of grasses and shrubs, and $6 \%$ water body that includes lakes and ponds. The grasses and bushes are considered as open as these are covered by the snow during the winter. Temperature and precipitation lapse rates within the watershed are calculated using the ClimateWNA-generated monthly climate data.

Thirteen parameters are chosen for the calibration. Of the 13 , four parameters are related to the snow module, three related to soil module, four to runoff transfer and two to climate modules. These parameters are the most sensitive parameters and often the main parameters calibrated by other published studies that have used the HBV model. Initial ranges of the parameter values that are calibrated are taken from the default values provided in the HBV-EC manual (Canadian Hydraulic Centre, 2010) and values reported in the previous studies (Hamilton et al., 2000; Jost et al., 2012; Stahl et al., 2008; Zégre et al., 2010). The model was calibrated using the optimization algorithm Genoud (written in the rgenoud $\mathrm{R}$ application; Mebane and Sekhon, 2011) that combines evolutionary algorithm methods with a steepest gradient descent algorithm (Jost et al., 2012) to maximize the Nash-Sutcliffe efficiency (NSE) (Nash and Sutcliffe, 1970) of the streamflow.

\subsubsection{Application}

The calibrated model is driven by the LARS-WG-generated daily climates to simulate the streamflows for reference and future periods. Reference period model-simulated streamflow is compared with observed flow to determine how well the LARS-WG-generated climate can represent the properties of the observed streamflow. Simulated streamflows for the reference and future periods are compared to assess the climate change impacts.

\subsubsection{Parameter uncertainty}

Equifinality or the ability for multiple acceptable models with combination of different parameter sets that can be obtained as representations of hydrological behavior, introduces uncertainty into the model estimates.Uncertainty in the model predictions can be addressed by generating the random samples from the parameter space, and picking up and analyzing the parameter sets that produce the best results (Stahl et al., 2008). However, in the high-dimensional parameter space, random sampling may not guarantee that best parameter set can be found even with the large numbers of model runs (Jost et al., 2012). The generalized likelihood uncertainty estimation (GLUE) methodology can provide model evaluation and model uncertainly when equifinality exists with the high-dimensional parameter space (Beven and Freer, 2001). For this analysis we followed a guided GLUE approach used by Jost et al. (2012), which is a simplified version of the original GLUE approach presented by Beven and Freer (2001) and Freer et al. (1996).

First, we define expanded bounds for the parameters to be calibrated. Next we use Genoud (Mebane and Sekhon, 2011), an optimization algorithm in $\mathrm{R}$, to calibrate and produce a model with the NSE or the generalized likelihood measure. The Genoud algorithm combines an evolutionary algorithm method with a steepest gradient descent algorithm to solve difficult optimization problems (Jost et al., 2012). Following the calibration, if optimal parameters are sampled near the preselect bounds, the prior parameter bounds are widened and Genoud algorithm is re-run. Once an optimal parameter set is identified, the model is set for 10000 runs using the latin hypercube search (LHS) technique to produce 100 most efficient model parameter sets that result in NSE values higher than the optimal less value. The optimal less value is selected as NSE minus 0.1. These 100 parameter sets are used with HBV-EC to provide a range of model results to help understand the model sensitivity to the parameter uncertainties. 

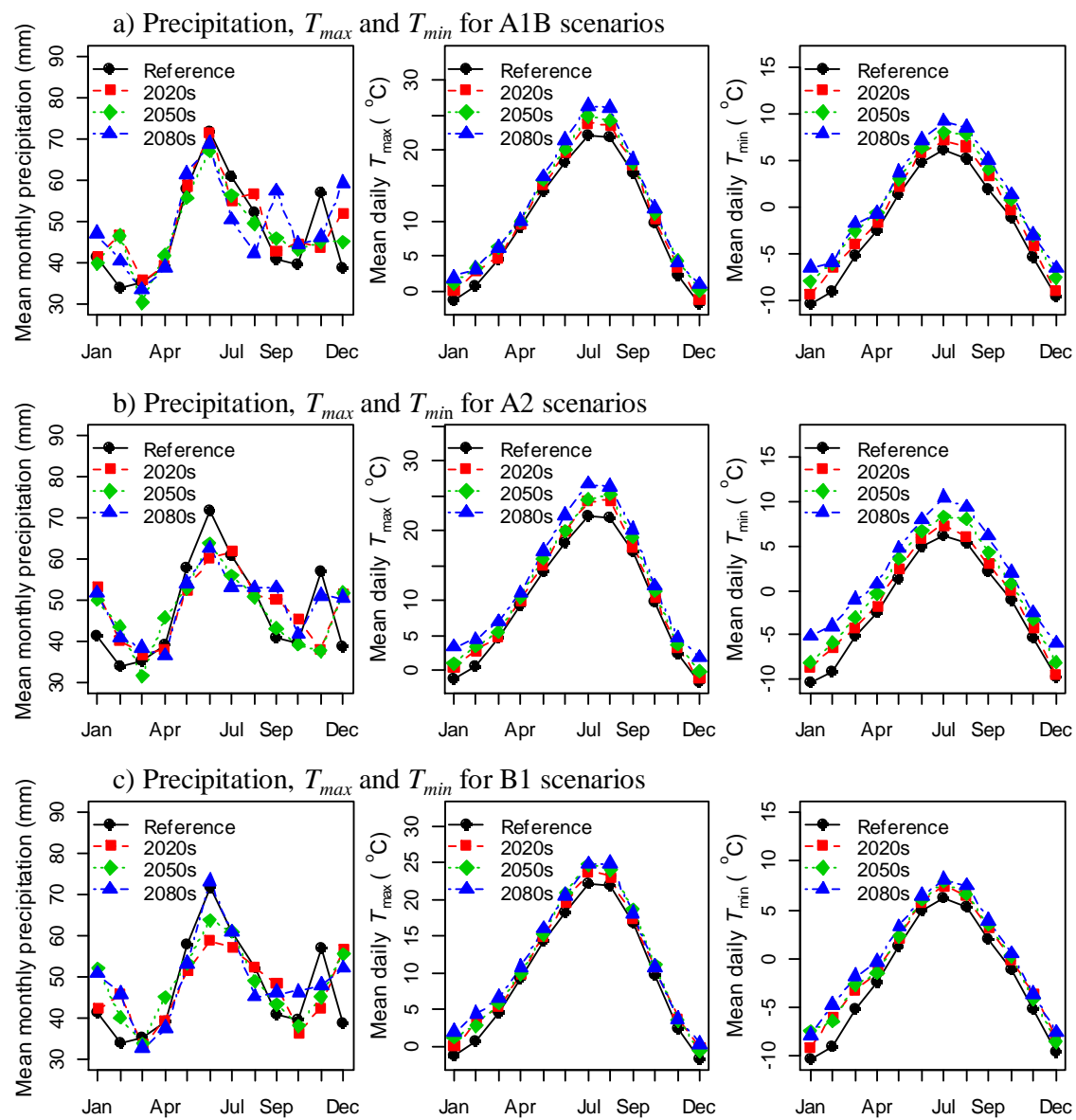

Fig. 2. Reference (observed) period daily climates aggregated to monthly scale and nine sets of future monthly climate means (precipitation, $T_{\max }$ and $T_{\min }$ ) estimated for climate station, Coleman.

\subsubsection{Forest change/removal}

This project parallels another project investigating the effects of a 2003 wildfire and some salvage harvesting on the hydrology of the headwater catchments following methodology that compares the catchment hydrology before and after the removal of forest, presented by Seibert et al. (2010). The objective is to investigate a worst-case scenario due to climate change and forest removal. Using a relatively simple conceptual model (e.g., HBC-EC) to simulate streamflow with simple precipitation and temperature input data does limit the ability to describe detailed forest processes (e.g., interception, transpiration, and changed in radiation, sensible and latent heat fluxes and energy balance (e.g., Mahat and Tarboton, 2012; Mahat et al., 2013)) using physical processes. However, HBV-EC parameters such as interception factor and MRF (ratio between melt factor in forest to melt factor in open; see Table 3) allow the simulation of different land covers by calibrating the differences in precipitation interception and snowmelt processes between the forest and the open areas. Under our scenario of catastrophic change and no forest regrowth, the parameters controlling interception and snowmelt process are likely the most important process in the mountainous regions where catchment hydrology is dominated by the snowmelt.

We, however, found that many parameters in HBV-EC interact, causing the possibility of unrealistic calibration parameters RFCF (rainfall correction factor) and SFCF (snowfall correction factor) values. For example, calibration of interception in addition to the parameters RFCF and SFCF results in a negative number when rain/snow gauge catch deficiency is larger than the forest snow interception loss. So, we fix the interception parameters based on some available data and focus our efforts on the calibration of the MRF parameter for the watershed in reference condition for the forest change analysis. To investigate the importance of the forest in the hydrology of the region and how it interacts with changing climate, the forest was completely removed from the watershed by substituting the parameter set of open area to approximate the effect of a catastrophic forest wildfire. 


\section{Results}

\subsection{Estimates of future monthly climate means}

Relative changes in watershed averaged monthly climate means observed in GCM outputs for nine different future scenarios are presented in Table 1. GCM projections showed an increase in precipitation during winter (December, January and February) and a decrease in precipitation during summer (June, July and August) in our watershed. Projections for spring (March, April and May) and fall (September, October and November) were mixed. There was a consistent increase in mean temperature for all seasons of the year (Table 1).

Future monthly climate means (precipitation, $T_{\max }$ and $\left.T_{\min }\right)$ at the Coleman climate station for the nine scenarios, along with the reference period observed climate aggregated to monthly scale, are presented in Fig. 2. Disaggregation of these provides climate inputs to the hydrological model to simulate reference and future periods' streamflows. Figure 2 shows higher precipitation during winter and lower precipitation during summer for future periods in comparison to the reference period. However, the increase or decrease in future periods' precipitation compared to reference period was less than $10 \%$ for any seasons. $T_{\max }$ and $T_{\min }$ for future periods are higher for all seasons.

\subsection{Disaggregation}

LARS-WG model performance was evaluated by comparing the observed and LARS-WG-generated means and variances for monthly precipitation by using $t$ and $F$ test, respectively, and means of daily $T_{\max }$ and $T_{\min }$ by using the $t$ test (Table 2). LARS-WG reproduced $100 \%$ (for all twelve months) of monthly means for precipitation giving $p$ values higher than 0.05 , suggesting that there is not a significant difference in means at the $95 \%$ confidence level as shown in Table 2. However, only $75 \%$ of monthly variances for precipitation were reproduced by the model ( 4 out of $12 p$ values for the $F$ test are less than 0.05). LARS-WG produced mixed results for $T_{\min }$ and $T_{\max }$. The $t$ tests for the $T_{\min }$ were significant for 4 out of 12 months ( 4 out of $12 p$ values for the $t$ test are less than 0.05) and the $t$ tests for the $T_{\max }$ were significant for 1 out of 12 months ( 1 out of $12 p$ values for the $t$ test are less than 0.05). Comparison of LARS-WG-generated mean monthly precipitation and monthly mean daily $T_{\max }$ and $T_{\min }$ with observed climates are presented in the Fig. 3.

\subsection{HBV-EC calibration}

The Genoud function sampled few parameters near the range boundary in the first simulation. The parameter ranges were then widened to achieve the best-matched observed streamflow data with optimized parameters. With more than 15000 runs, an NSE of 0.82 was obtained in the second simulation with the parameter values within the selected ranges.
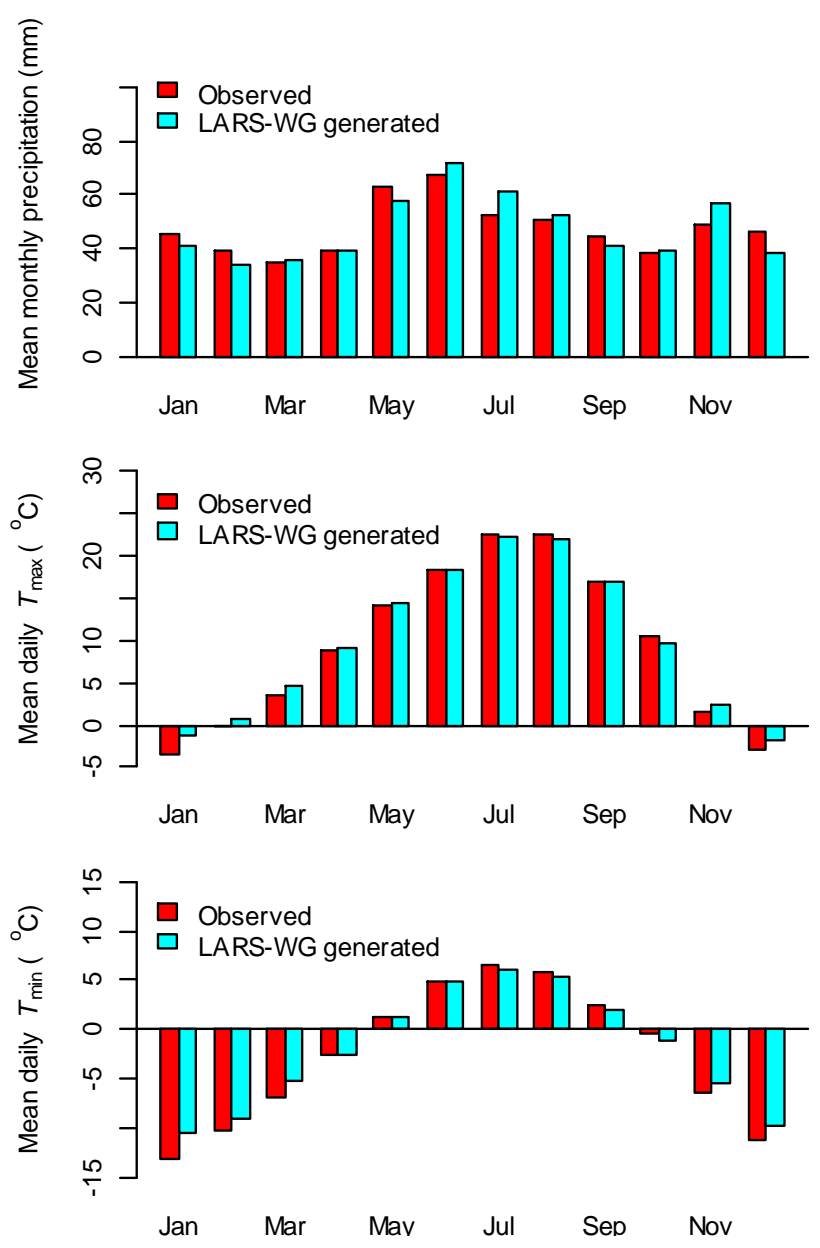

Fig. 3. Observed and LARS-WG-generated mean monthly precipitation, and monthly mean daily $T_{\max }$ and $T_{\min }$.

Different components of the HBV-EC model, model parameters and calibrated values are presented in Table 3.

Figure 4 compares the observed daily streamflow at the watershed outlet, Crowsnest at Frank, with HBV-ECsimulated values for the calibration period 1965-1997. Both high and low flows were simulated reasonably well, except a few larger peaks that were underestimated by the model (Fig. 4). Differences in mean monthly streamflow between the observed and simulated values (observed-simulated) range from $-15 \%$ to $50 \%$. The largest difference observed was during the month of February. Though the difference was large in percentage, in terms of magnitude the difference was very small, about $5 \mathrm{~mm}$. A maximum of $12 \mathrm{~mm}$ difference was observed in the month of June. Differences between the observed and simulated annual flows range from $-25 \%$ to $40 \%$. The largest differences $(>|15 \%|)$ observed were during the years 1968, 1969, 1973, 1974,1988, 1991 and 1994. In other years the differences were less than $15 \%$. While there were discrepancies in the simulated versus observed mean monthly and annual flows, the negative and positive 
Table 1. Relative changes in watershed averaged monthly GCM projections of precipitation and air temperature in comparison to reference periods' climates for A1B, A2 and B1 scenario for 2020s, 2050s, and 2080s time periods. Annual is the relative changes in mean annual climate (precipitation and temperature) in future projections in relation to the reference periods' climates. Annual mean is the mean of three annuals for the A1B, A2 and B1 scenarios.

\begin{tabular}{|c|c|c|c|c|c|c|c|c|c|c|c|c|c|c|c|}
\hline $\begin{array}{l}\text { Time } \\
\text { period }\end{array}$ & Scenario & Jan & Feb & Mar & Apr & May & Jun & Jul & Aug & Sep & Oct & Nov & Dec & Annual & $\begin{array}{r}\text { Annual } \\
\text { mean }\end{array}$ \\
\hline \multicolumn{16}{|c|}{ Percentage change in mean monthly precipitation, $\Delta P$} \\
\hline \multirow{3}{*}{$\begin{array}{l}\text { 2011-2040 } \\
\text { (“2020s”) }\end{array}$} & A1B & 2.6 & 4.1 & -4.3 & 3.9 & -7.3 & -5.0 & -2.4 & -2.8 & 3.2 & -2.7 & -7.9 & 3.6 & -1.6 & \multirow[t]{3}{*}{-1.708} \\
\hline & $\mathrm{A} 2$ & 3.1 & 3.8 & -4.5 & 3.5 & -7.3 & -5.2 & -2.3 & -3.1 & 2.7 & -2.6 & -7.7 & 3.6 & -1.6 & \\
\hline & B1 & 2.3 & 3.6 & -4.2 & 3.9 & -7.8 & -5.6 & -2.6 & -3.6 & 2.8 & -3.5 & -7.7 & 3.4 & -1.9 & \\
\hline \multirow{3}{*}{$\begin{array}{l}2041-2070 \\
\text { (“2050s”) }\end{array}$} & A1B & 4.2 & 4.7 & -2.9 & 4.9 & -6.6 & -4.6 & -1.6 & -1.8 & 4.3 & -1.9 & -6.7 & 4.8 & -0.6 & \multirow[t]{3}{*}{-0.980} \\
\hline & $\mathrm{A} 2$ & 3.7 & 4.4 & -3.0 & 5.0 & -6.1 & -4.5 & -1.3 & -1.5 & 4.3 & -1.9 & -7.0 & 4.5 & -0.6 & \\
\hline & B1 & 3.7 & 2.6 & -3.6 & 3.8 & -7.9 & -5.2 & -2.0 & -3.2 & 3.0 & -3.4 & -7.5 & 3.1 & -1.7 & \\
\hline \multirow{3}{*}{$\begin{array}{l}\text { 2071-2100 } \\
\text { (“2080s") }\end{array}$} & $\mathrm{A} 1 \mathrm{~B}$ & 5.3 & 4.4 & -1.9 & 4.6 & -6.0 & -3.8 & -0.6 & -1.0 & 4.9 & -1.3 & -6.4 & 6.3 & 0.04 & \multirow[t]{3}{*}{0.002} \\
\hline & A2 & 6.7 & 6.8 & -1.2 & 6.1 & -5.0 & -3.1 & 0.5 & -0.1 & 6.1 & -0.6 & -6.0 & 6.8 & 1.1 & \\
\hline & $\mathrm{B} 1$ & 3.9 & 4.5 & -2.7 & 4.5 & -6.9 & -5.2 & -2.0 & -2.5 & 3.5 & -3.2 & -7.0 & 4.2 & -1.1 & \\
\hline \multicolumn{16}{|c|}{ Change in monthly mean daily air Temperature, $\left(\Delta T_{\max }+\Delta T_{\min }\right) / 2$} \\
\hline \multirow{3}{*}{$\begin{array}{l}2011-2040 \\
\text { (“2020s”) }\end{array}$} & $\mathrm{A} 1 \mathrm{~b}$ & 1.6 & 3.1 & 0.9 & 0.7 & 1.0 & 1.6 & 1.5 & 1.7 & 1.5 & 0.8 & 0.9 & 0.7 & 1.3 & \multirow[t]{3}{*}{1.4} \\
\hline & $\mathrm{A} 2$ & 2.0 & 2.8 & 0.6 & 0.4 & 1.2 & 1.7 & 1.8 & 1.8 & 1.1 & 0.9 & 1.0 & 0.8 & 1.3 & \\
\hline & $\mathrm{B} 1$ & 1.7 & 3.6 & 1.5 & 1.0 & 1.1 & 1.3 & 1.6 & 1.3 & 1.2 & 1.2 & 1.1 & 1.1 & 1.5 & \\
\hline \multirow{3}{*}{$\begin{array}{l}2041-2070 \\
\text { (“2050s”) }\end{array}$} & A1B & 3.1 & 3.6 & 2.2 & 1.2 & 1.7 & 2.0 & 2.5 & 2.7 & 2.2 & 1.7 & 2.0 & 1.8 & 2.2 & \multirow[t]{3}{*}{2.1} \\
\hline & A2 & 2.6 & 3.4 & 1.8 & 1.6 & 2.2 & 2.0 & 2.4 & 3.0 & 2.6 & 1.9 & 1.6 & 1.6 & 2.2 & \\
\hline & B1 & 3.0 & 2.7 & 2.0 & 0.9 & 0.9 & 2.4 & 2.5 & 1.9 & 1.9 & 1.3 & 1.4 & 0.8 & 1.8 & \\
\hline \multirow{3}{*}{$\begin{array}{l}\text { 2071-2100 } \\
\text { (“2080s") }\end{array}$} & A1B & 3.8 & 3.2 & 2.9 & 1.0 & 2.4 & 3.1 & 3.7 & 3.5 & 2.8 & 2.1 & 2.4 & 3.0 & 2.8 & \multirow[t]{3}{*}{3.0} \\
\hline & A2 & 5.2 & 5.3 & 3.3 & 2.2 & 3.4 & 3.7 & 4.5 & 4.6 & 4.0 & 2.7 & 2.8 & 3.6 & 3.8 & \\
\hline & B1 & 3.8 & 4.3 & 3.0 & 1.6 & 2.1 & 2.1 & 2.4 & 2.7 & 1.8 & 1.3 & 1.8 & 1.8 & 2.4 & \\
\hline
\end{tabular}

errors offset each other giving only $6 \%$ (about $25 \mathrm{~mm}$ ) difference in mean annual flow between the observed and simulated values.

To verify the representation of precipitation in mountains in the model, mean cumulative precipitation derived from the Coleman station was compared with the available few years of precipitation data recorded at Ironstone climate station located at higher elevation (Fig. 5). Though this comparison was for the summer precipitation only, the agreement between the observed and derived values in Fig. 5 indicates that the model has reasonably represented the precipitation in the mountain during the summer. Observed snow data at nearby stations were not available for comparison.

\subsection{HBV-EC application}

Figure 6 compares the model-simulated streamflow (daily, monthly and annual) with the observed streamflow values at the study watershed outlet, Crowsnest at Frank. Input to the HBV-EC in this case is LARS-WG-generated daily realizations. Daily, monthly and annual comparisons (Fig. 6) show that the simulated streamflow is realistic and close to the observed values as in Fig. 4. However, in this case, difference in mean monthly streamflow between the observed and simulated values was found up to $60 \%$ in February. Though the difference was large in percentage, in terms of magnitude the difference was very small, about $6 \mathrm{~mm}$. A maximum of $20 \mathrm{~mm}$ difference was observed in the month of June.

Figure 7 compares the mean monthly streamflow simulated using observed climate forcing with the mean monthly streamflow simulated using LARS-WG-generated climate forcing. While they both underestimated the observed monthly streamflow, these simulations were found to be highly correlated.

Simulations from LARS-WG climates showed up to $90 \%$ (in year 1983, see Fig. 6) difference between the observed and simulated annual flow values. However, while there were discrepancies in the simulated versus observed mean monthly and annual flows, the negative and positive errors offset each other, giving only $9 \%$ (about $37 \mathrm{~mm}$ ) difference in mean annual flow between the observed and simulated values.

Compared to simulations from the observed climate forcing, simulations from the LARSE-WG climate forcing had larger errors. NSE value for LARS-WG-simulated daily flow was found to be only 0.55 . But this is somewhat expected given that the generated weather data capture the statistics but not the actual amounts. However, we believe that the error that LARS-WG produced in reference condition is inherent, would be consistent in both reference and future period 

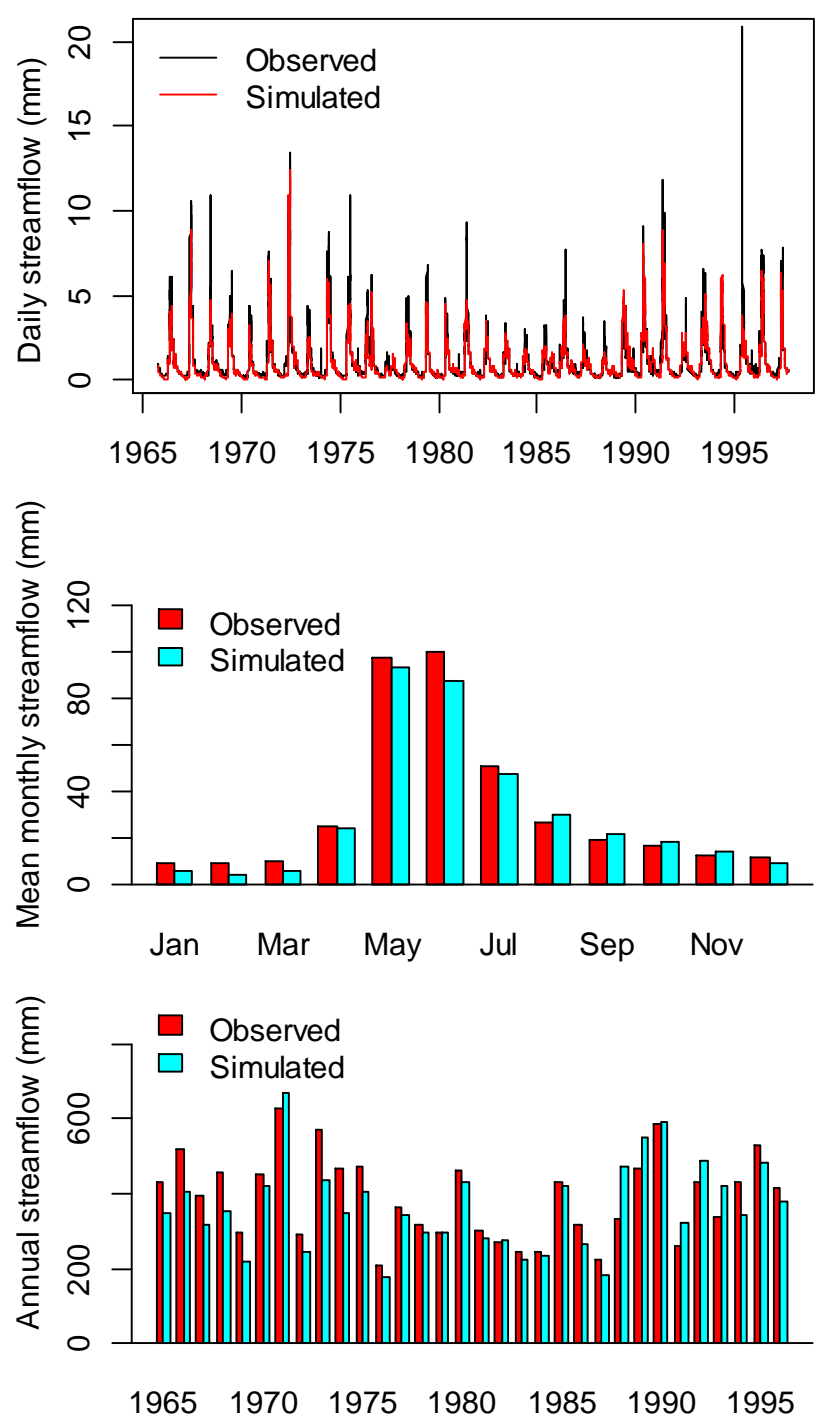

Fig. 4. Observed and HBV-EC-simulated daily, monthly and annual streamflows during the calibration period from 1965 to 1997 . HBV$\mathrm{EC}$ is driven by the daily climates observed at Coleman station.

simulations, and would not affect the evaluation of climate and forest change impact.

Figure 8 compares the HBV-EC-simulated streamflows at the watershed outlet, Crowsnest at Frank, for the reference period and nine future periods. Mean monthly hydrographs of all future simulations (Fig. 8) showed an early initiation of peaks resulting in the seasonal shift, a shift toward higher spring (March, April) flows and a corresponding decrease in summer (June and July) flows associated with the shift in the spring flows compared to the reference period hydrographs. Future simulations also showed an increase in the winter low flows. Winter low flows increased up to $200 \%(9.3 \mathrm{~mm})$ in February, while summer high flows decreased up to $63 \%$ $(31.2 \mathrm{~mm})$ in June in the A2 scenario in the 2080s time period. Fall (September, October and November) flows were

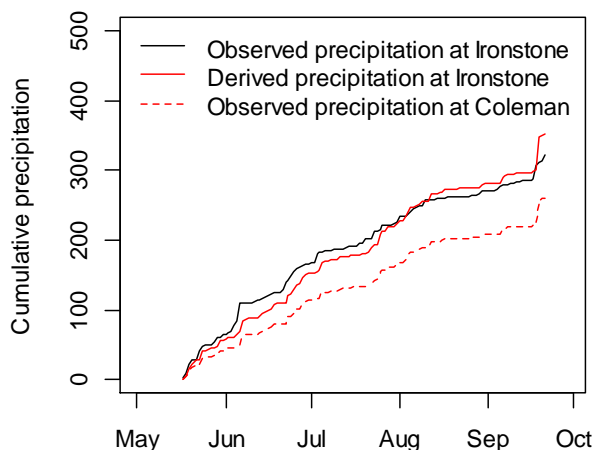

Fig. 5. Mean cumulative precipitation at Coleman, and observed and derived mean cumulative precipitation for the climate station Ironstone.
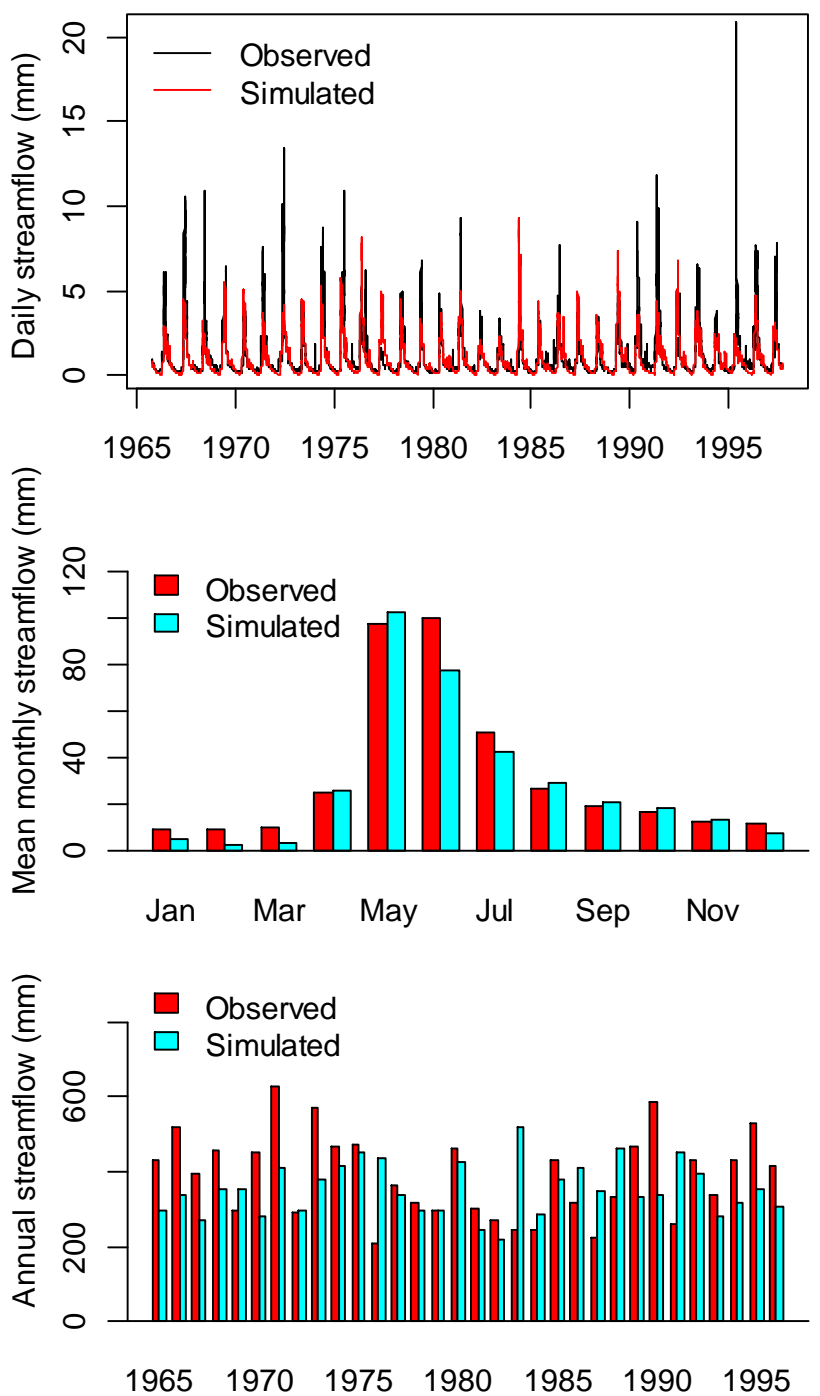

Fig. 6. Same as Fig. 4, but in this case HBV-EC is driven by the LARS-WG-generated daily climates. 
Table 2. Comparison of monthly statistics of daily precipitation, $T_{\max }$ and $T_{\min }$ observed at Coleman station during the period from 1965 to 1997 with synthetic data generated by LARS-WG. $P$ values calculated by the $t$ test and $F$ test for the monthly means and variances are shown. A probability of 0.05 or lower indicates a departure from the observations that is significant at the $5 \%$ level.

\begin{tabular}{|c|c|c|c|c|c|c|c|c|c|c|c|c|}
\hline & Jan & $\mathrm{Feb}$ & Mar & Apr & May & Jun & Jul & Aug & Sep & Oct & Nov & Dec \\
\hline \multicolumn{13}{|l|}{ Precipitation } \\
\hline Observed mean & 45.10 & 39.13 & 34.98 & 39.03 & 63.24 & 67.58 & 52.56 & 50.98 & 44.42 & 38.19 & 48.70 & 45.91 \\
\hline Observed standard deviation & 31.80 & 31.59 & 21.59 & 17.63 & 29.39 & 26.19 & 40.22 & 39.99 & 26.67 & 24.34 & 33.15 & 30.23 \\
\hline Generated mean & 41.36 & 33.85 & 35.42 & 39.34 & 57.96 & 71.61 & 60.82 & 52.11 & 41.01 & 39.62 & 56.99 & 38.60 \\
\hline Generated standard deviation & 21.67 & 17.00 & 20.24 & 17.64 & 25.49 & 25.81 & 23.65 & 20.02 & 22.19 & 21.19 & 32.38 & 22.44 \\
\hline$P$ values for $t$ test & 0.583 & 0.406 & 0.933 & 0.943 & 0.442 & 0.535 & 0.319 & 0.887 & 0.577 & 0.803 & 0.315 & 0.276 \\
\hline$P$ values for $F$ test & 0.036 & 0.001 & 0.720 & 0.995 & 0.431 & 0.936 & 0.03 & 0.03 & 0.309 & 0.445 & 0.896 & 0.102 \\
\hline \multicolumn{13}{|l|}{$T_{\min }$} \\
\hline Observed mean & -13.05 & -10.09 & -6.87 & -2.63 & 1.35 & 4.95 & 6.61 & 5.86 & 2.46 & -0.46 & -6.39 & -11.15 \\
\hline Observed standard deviation & 4.76 & 4.06 & 2.93 & 1.69 & 0.95 & 1.16 & 1.02 & 1.20 & 1.38 & 1.58 & 3.16 & 4.32 \\
\hline Generated mean & -10.41 & -9.10 & -5.21 & -2.51 & 1.32 & 4.93 & 6.15 & 5.33 & 2.07 & -1.13 & -5.30 & -9.67 \\
\hline Generated standard deviation & 1.82 & 1.72 & 1.32 & 0.83 & 0.65 & 0.71 & 0.49 & 0.63 & 0.97 & 1.21 & 1.44 & 1.73 \\
\hline$P$ values for $t$ test & 0.005 & 0.208 & 0.005 & 0.734 & 0.914 & 0.944 & 0.024 & 0.031 & 0.188 & 0.062 & 0.080 & 0.078 \\
\hline \multicolumn{13}{|l|}{$T_{\max }$} \\
\hline Observed mean & -3.51 & -0.02 & 3.55 & 8.91 & 14.22 & 18.38 & 22.37 & 22.36 & 16.90 & 10.41 & 1.66 & -2.83 \\
\hline Observed standard deviation & 4.07 & 3.14 & 2.85 & 2.21 & 1.85 & 1.84 & 2.14 & 2.55 & 3.43 & 2.23 & 2.91 & 3.34 \\
\hline Generated mean & -1.25 & 0.64 & 4.64 & 9.21 & 14.24 & 18.30 & 22.12 & 21.84 & 16.85 & 9.66 & 2.33 & -1.86 \\
\hline Generated standard deviation & 1.38 & 1.13 & 0.83 & 1.09 & 1.22 & 0.93 & 1.08 & 1.04 & 1.38 & 1.30 & 1.10 & 1.19 \\
\hline$P$ values for $t$ test & 0.006 & 0.263 & 0.052 & 0.499 & 0.957 & 0.826 & 0.558 & 0.282 & 0.935 & 0.106 & 0.227 & 0.128 \\
\hline
\end{tabular}

affected less and remained almost the same for all future periods. Despite the variations in the mean monthly flows, mean annual flows for the reference and future periods were quite similar (Fig. 8). Maximum increase in mean annual flow was projected to be approximately $9 \%$ in the 2080 s for the A2 scenario, while the maximum decrease was projected to be approximately $6 \%$ in the 2050 s for the A1B scenario.

The reference and future periods' mean monthly snow water equivalent (SWE) and mean monthly evapotranspiration for the study watershed are presented in Fig. 9. SWE values decreased in all future simulations. Evapotranspiration increased in spring and decreased in summer. Despite an increase in temperature throughout the year, a decrease in evapotranspiration during the summer indicates a water deficit during the summer.

\subsection{Parameter uncertainty}

Ranges of values for the best 100 calibrated parameter sets that are obtained from 10000 runs performed using the LHS technique are presented in Table 3. During the simulations NSE values were obtained in the range of 0.72 to 0.82 . Using the 100 best parameter sets, ensembles of simulations for the reference and future periods were performed and relative changes in mean monthly streamflows in different future periods compared to the reference period were calculated (Fig. 10). Ensemble spread was found to be higher in spring and summer than in winter and fall in all future scenarios, indicating higher parameter uncertainty impacts on

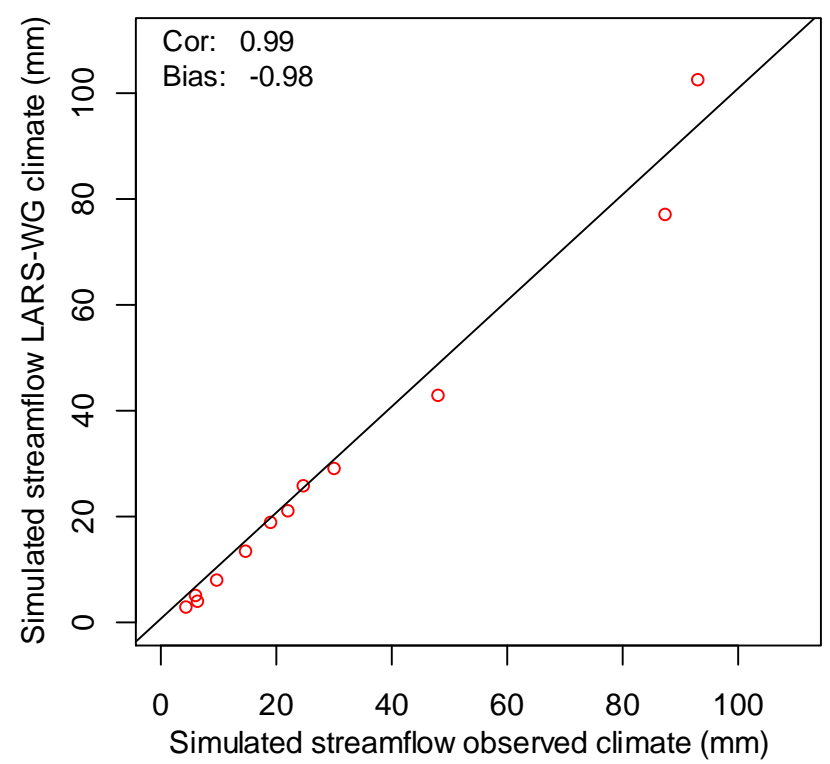

Fig. 7. Comparison of mean monthly streamflow simulated using daily observed climate forcing with mean streamflow simulated using LARS-WG-generated daily climate forcing.

spring and summer flows than on winter and fall flow. Single simulation showed a maximum of about $31.2 \mathrm{~mm}$ of streamflow reduction during summer in the 2080s for the A2 scenario, while the ensemble showed up to an $80 \mathrm{~mm}$ reduction in streamflow in summer in 2080s for the same scenario. The 
A1B
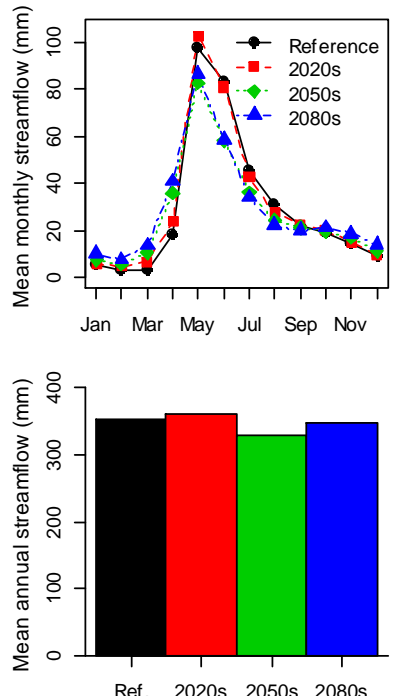

A2
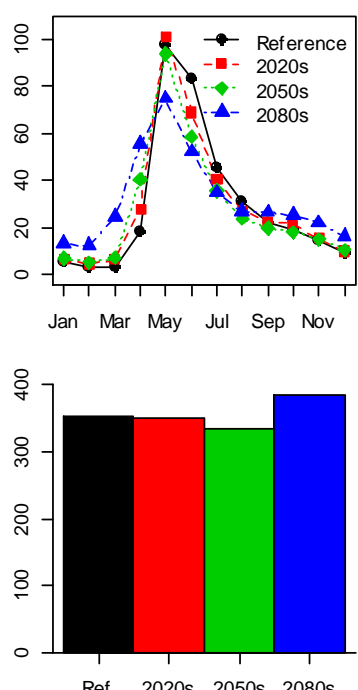

B1
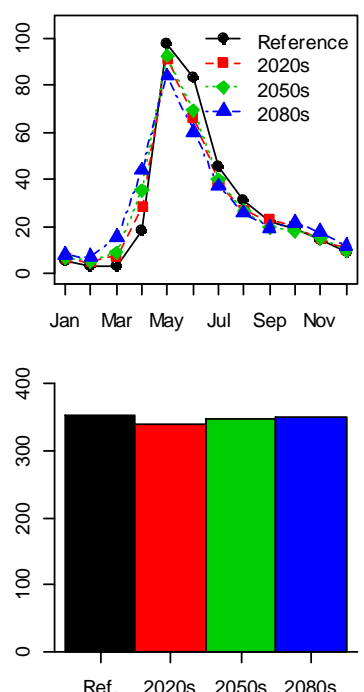

Fig. 8. HBV-EC-simulated mean monthly and mean annual streamflows for the reference and nine future periods (for three different scenarios: A1B, A2 and B1; and for three different time periods: 2020s, 2050s and 2080s) at the watershed outlet at Crowsnest at Frank. Both reference and future period inputs to the HBV-EC is the daily climate data generated by LARS-WG.

Table 3. Modules, description of calibrated parameters, calibrated parameter values and ranges of the 100 best parameter sets.

\begin{tabular}{|c|c|c|c|}
\hline Model module & Parameter & Description & Calibrated value \\
\hline \multirow[t]{8}{*}{ Snow } & AM & Influence of aspect/slope on melt factor & 0.45 \\
\hline & & & $0.01-0.98$ \\
\hline & $\mathrm{CM}$ & Melt factor for winter solstice in open areas $\left(\mathrm{mm}^{\circ} \mathrm{C}^{-1} \mathrm{day}^{-1}\right)$ & 0.06 \\
\hline & & & $0.01-1.0$ \\
\hline & DC & Increase of melt factor between winter and summer solstice $\left(\mathrm{mm}^{\circ} \mathrm{C}^{-1} \mathrm{day}^{-1}\right)$ & 3.45 \\
\hline & & & $2.02-5.89$ \\
\hline & MRF & Ratio between melt factor in forest and melt factor in open & 0.70 \\
\hline & & & $0.40-0.95$ \\
\hline \multirow[t]{6}{*}{ Soil } & LP & Soil moisture content threshold where evaporation becomes limited & 0.61 \\
\hline & & & $0.6-0.90$ \\
\hline & FC & Soil field capacity & 132 \\
\hline & & & $107-250$ \\
\hline & $\beta$ & Controls relationship between soil infiltration and soil water release & 0.67 \\
\hline & & & $0.51-1.90$ \\
\hline \multirow{8}{*}{$\begin{array}{l}\text { Runoff } \\
\text { transfer }\end{array}$} & $\mathrm{KF}$ & Proportion of fast reservoir release $\left(\mathrm{day}^{-1}\right)$ & 0.00026 \\
\hline & & & $0.0001-0.004$ \\
\hline & $\alpha$ & Exponent to adjust release rate of fast reservoir & 1.12 \\
\hline & & & $0.48-1.67$ \\
\hline & $\mathrm{KS}$ & Proportion of slow reservoir release $\left(\right.$ day $\left.^{-1}\right)$ & 0.03 \\
\hline & & & $0.0002-0.05$ \\
\hline & FRAC & Fraction of runoff directed to fast reservoir & 0.90 \\
\hline & & & $0.7-0.99$ \\
\hline \multirow[t]{4}{*}{ Climate } & RFCF & Rainfall correction factor & 0.87 \\
\hline & & & $0.81-1.20$ \\
\hline & SFCF & Snowfall correction factor & 1.12 \\
\hline & & & $0.83-1.40$ \\
\hline
\end{tabular}




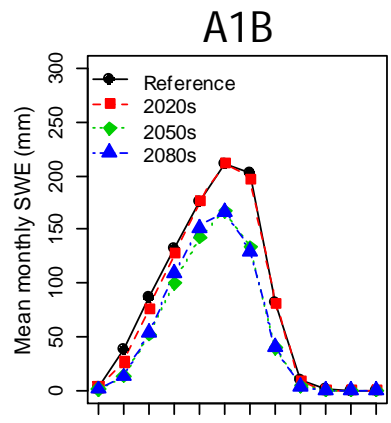

Oct Dec Feb Apr Jun Aug

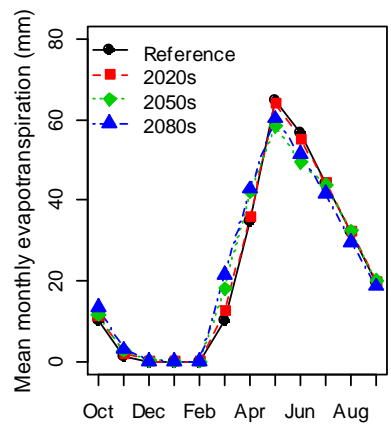

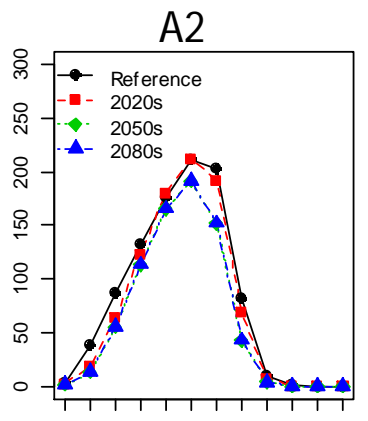

Oct Dec Feb Apr Jun Aug

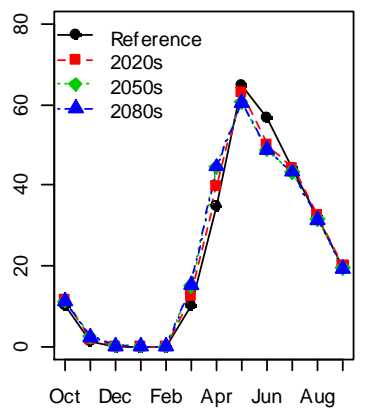

B1

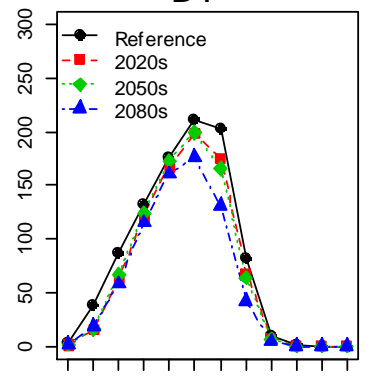

Oct Dec Feb Apr Jun Aug

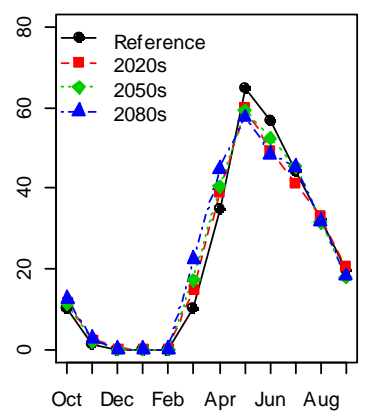

Fig. 9. HBV-EC-simulated watershed averaged mean monthly snow water equivalent (SWE) and mean monthly evapotranspiration for the reference and future periods.

ensemble mean showed approximately a $46 \mathrm{~mm}$ reduction in summer flow, which is about 1.5 times higher than what the single simulation predicted.

\subsection{Forest change/removal}

Ensemble streamflows were generated using the best 100 parameter sets to assess the forest change impacts to the streamflow in the reference and future periods. The forest change impact assessed for the future period is the combined forest and the climate change impacts. The worst-case climate condition, the 2080s with A2 climate scenario, was combined with the forest change scenario to represent the possible worst-case future scenario. Figure $11 \mathrm{a}, \mathrm{b}$ and $\mathrm{c}$ show relative changes in mean monthly streamflow (ensemble and mean) due to forest removal (Fig. 11a), due to climate change (Fig. 11b), and due to combined forest removal and climate change (Fig. 11c). Ensemble means of these are put together in Fig. 11d. The removal of forest from the watershed in the reference period increased the streamflow in early spring, late summer and early fall, and reduced the streamflow in late spring and early summer. The means ensembles (Fig. 11d) show a higher increase in winter flow due to the combined forest removal and climate change impacts compared to an individual impact produced by forest removal or climate change. However, the combined impact on the summer flow was less compared to the climate-only change impact, suggesting that the forest had a role in the summer evapotranspiration and streamflow in summer.

\section{Discussion}

This study uses GCM outputs downscaled using the ClimateWNA model with two other models, LARS-WG and HBV-EC, to assess the impacts of climate and forest changes on streamflow. Large sources of uncertainty exist in the climate models. Climate projection depends on a number of unpredictable socio-economic as well as natural processes and technology that emissions of greenhouse gases and warming of the atmosphere depend on. Uncertainties also exist on the model formulations: assumptions of initial and boundary conditions, model parameterizations and structures, etc. Using a single GCM output and picking up a single optimum for a given climate adaptation would not address the uncertainty in climate projections. The climate sensitivity parameter is the most important source of uncertainty in the climate projections, and ensembles of simulations with a single model but different choices of various parameters may help to explore the uncertainty in the climate projections.

Precipitation and temperature lapse rate that are used in the downscaling in this study are derived from the interpolated climate surface based on standard weather stations. Weather station coverage is sparse over the high mountain areas compared to the plains or more populated parts of the country. It is impossible to assess the statistical accuracy of climate surface for the areas that lack station coverage, and these areas are more prone to error while downscaling.

So, the uncertainty is everywhere. Inclusion of uncertainty estimates in GCM simulations as well as in ClimateWNA 

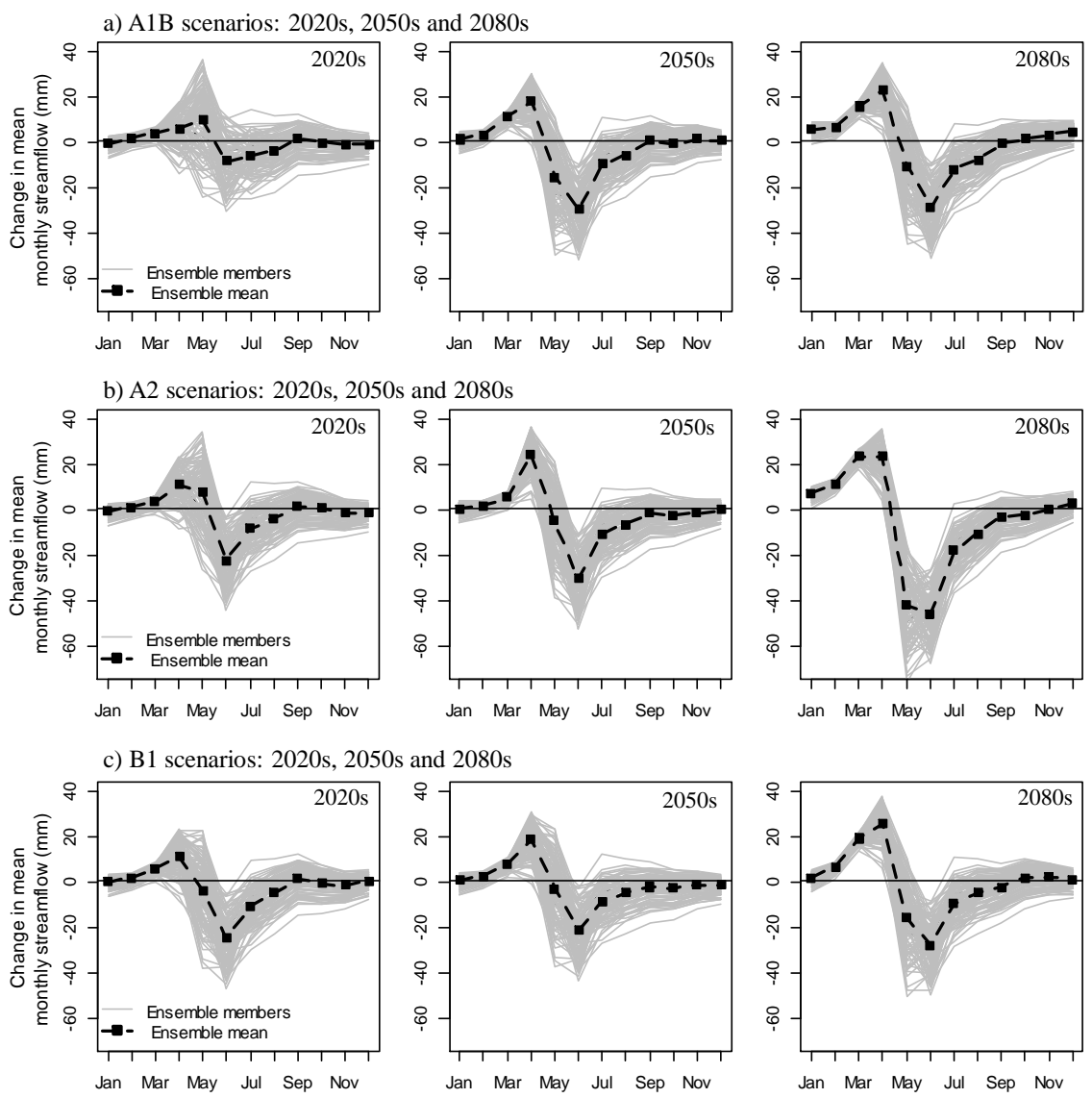

Fig. 10. Ensemble of relative changes in mean monthly streamflows in different future periods compared to reference period streamflow; and mean of the ensemble.

downscaling and LARS-WG disaggregation may provide the robust assessment of the impacts of climate change on water resource systems. But, in our study, it does not seem plausible to perform uncertainty analysis on all aspects of the modeling approaches used here; as hydrologists, however, we focused on the uncertainty analysis on the aspect of the hydrological modeling.

LARS-WG demonstrated a relatively poor performance in reproducing the monthly variances of $T_{\max }$ and $T_{\min }$. It, however, reproduced the average behavior of observed climate data in terms of mean. The possible source of error in the LARS-WG simulations could be associated with the use of many pre-set values in the model. While estimating an average daily standard deviation for $T_{\max }$ and $T_{\min }$, LARS-WG normalizes the temperature residuals using constant autocorrelations and cross-correlations between the temperature residuals. These constant values are site specific and might be different for our climate. Semenov and Brooks (1999) recommend site-specific testing and validation of the model before the generated data are used in a sensitive application, where more accuracy is required for each variable, for example, in a study of an extreme weather event. For other kinds of studies, they mention, LARS-WG can be implemented without any changes in the model.

The hydrological model used in this study is a conceptual model and does not represent many physical processes. However, the choice is governed by the availability of data. More detailed models may represent the physical processes thoroughly, but use of these models under such conditions may cause problems of over-parameterization, parameter estimation and validation limitations. Observed climate and other data available for model input and verification in our study were limited. Thus the hydrological model in this study was calibrated against the streamflow measurements only. It would have been better if we were able to calibrate the model against other measurements, i.e., SWE, soil moisture content or evapotranspiration, before the model was used to simulate future streamflows, but the limited data did not afford the luxury to validate the model against other measurements. We, to some extent, verified the spatial representation of summer precipitation in the model by comparing the model-derived summer precipitation for a higher elevation with the observation. However, the spatial representation of winter precipitation, i.e., the snow, was not verified as the observed data at the nearby station were not available. 

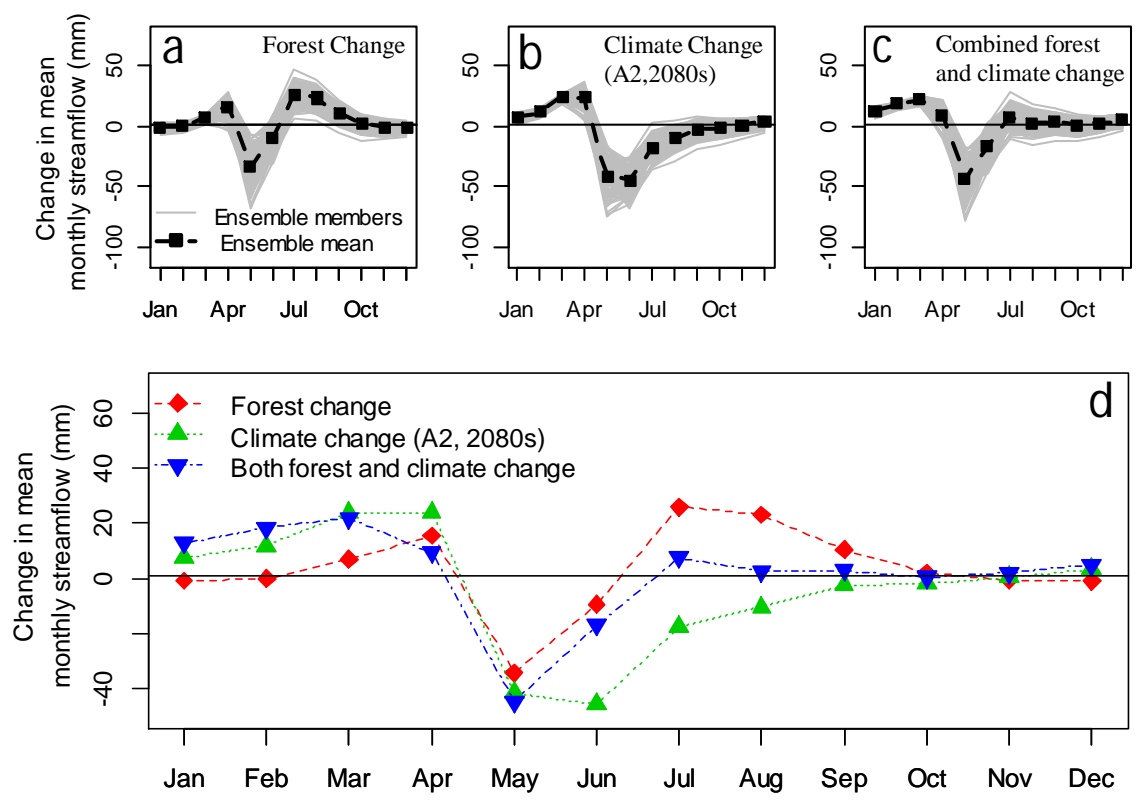

Fig. 11. Ensemble and mean values of relative changes in mean monthly streamflows: (a) due to forest removal, (b) due to climate change in 2080s in A2 scenario, and c) due to combined forest removal and climate change in 2080s in A2 scenario. Figure 9d shows the ensemble mean to compare the relative changes in mean monthly streamflows due to forest removal, due to climate change in 2080 s in A2 scenario and due to combined forest removal and climate change in 2080s in A2 scenario.

Comparison of HBV-EC-simulated flows for the reference and future periods suggests an amplification of the seasonal cycle with increased winter precipitation leading to a rise in winter (December, January and February) stream flow. Increase in streamflow during the winter could have been caused by the partial replacement of snowfall by rainfall due to the increase in temperature during the season when potential evapotranspiration rates are low (Forbes et al., 2011). The combination of increased temperature and decreased precipitation resulted in reduction in May and summer (June, July and August) streamflows. Previous climate change studies carried out in similar regions in Canada (e.g., Dibike and Coulibaly, 2005; Forbes et al., 2011; Kienzle et al., 2012) have also found the increased streamflows in winter and spring, and decreased streamflows in summer. We found that these changes (increased or decreased streamflows) were relatively higher for the $\mathrm{A} 2$ climate scenario, which is reflective of the largest changes to climate when compared to the other two scenarios.

The model parameter uncertainty analysis showed that streamflow predictions vary considerably. The higher spread observed in ensemble simulations in summer indicates a higher risk of lower summer flows than was predicted by the single simulation. Combined climate and forest change impacts compounded the effect of increasing winter flow; however, it did not reduce the summer flow. The higher winter or early spring flow in both reference and future periods observed after removal of forest may be caused by the quicker snowmelt when forest was removed. Usually the removal of forest results in increased summer flow due to less evapotranspiration during the summer or fall (Zhang et al., 2001). In our case the model does not distinguish the difference in evapotranspiration based on the presence or absence of the forest; thus the less reduction in the simulation of summer flow when forest was removed is possibly due to the higher soil moisture recharge during the winter that resulted in higher soil moisture release during the summer.

\section{Conclusions}

A watershed in the eastern slopes of the Southern Alberta Rocky Mountains was modeled to investigate the potential impacts of climate and forest changes on its hydrology using a simple conceptual hydrological model, HBV-EC. Monthly climate data downscaled to $1 \times 1 \mathrm{~km}$ grids are disaggregated to daily realizations using a stochastic weather generator, LARS-WG. These realizations provided the inputs to HBVEC to simulate reference and future scenarios' streamflows that are compared to assess the climate and forest change impacts. Climate change impacts were mainly observed in the seasonality of streamflow: higher winter flows and lower summer flows. These were mainly caused by the increase in temperature as there was not much difference in precipitation between reference and future periods. Summer flows were found to be more vulnerable, and the consequences are less availability of summer water in the river which is already stressed due to higher demand than supply. Removal of forest 
in both reference and future conditions had only little effects on streamflow compared to the pronounced effect of climate change. The compound effect of climate and forest changes on streamflow was more in winter and less in summer compared to individual effect of climate change. The use of an ensemble of parameter sets in this study allowed us to examine the impact of parameter uncertainty in the streamflow simulations. However, uncertainties exist in climate model outputs, downscaling and model simulations of many hydrologic components (i.e., soil moisture, base flow, snow accumulation and ablation, evapotranspiration, etc.) that are not analyzed in this study.

Acknowledgements. This research was supported by Alberta Innovates - Bio Solutions. We would like to thank George Jost from $\mathrm{BC}$ hydro, Vancouver, Canada for providing model optimization code and Nicolas Coops and his team from the University of British Columbia for providing climate data. We are also grateful to Professor Uldis Sillins and his team - Mike Wagner, Chris Williams and Amanda Martens from Renewable Resources Department, University of Alberta - for their support.

Edited by: S. Uhlenbrook

\section{References}

Arnell, N. W.: Climate change and global water resources, Global Environ. Change, 9, S31-S49, doi:10.1016/S09593780(99)00017-5, 1999.

Barnett, T. P., Adam, J. C., and Lettenmaier, D. P.: Potential impacts of a warming climate on water availability in snow-dominated regions, Nature, 438, 303-309, 2005.

Barnett, T. P., Pierce, D. W., Hidalgo, H. G., Bonfils, C., Santer, B. D., Das, T., Bala, G., Wood, A. W., Nozawa, T., Mirin, A. A., Cayan, D. R., and Dettinger, M. D.: Human-induced changes in the hydrology of the Western United States, Science, 319, 10801083, doi:10.1126/science.1152538, 2008.

Bergstrom, S. and Forsman, A.: Development of a conceptual deterministic rainfall-runoff model, Nord. Hydrol., 4, 147-170, 1973.

Beven, K. and Freer, J.: A dynamic TOPMODEL, Hydrol. Process., 15, 1993-2001, 2001.

Bladon, K. D., Silins, U., Wagner, M. J., Stone, M., Emelko, M. B., Mendoza, C. A., Devito, K., and Boon, S.: Wildfire and salvage logging impacts on nitrogen export from headwater streams in southern Alberta's Rocky Mountains, Can. J. Forest Res., 38, 2359-2371, 2008.

Campbell, J. L., Driscoll, C. T., Pourmokhtarian, A., and Hayhoe, K.: Streamflow responses to past and projected future changes in climate at the Hubbard Brook Experimental Forest, New Hampshire, United States, Water Resour. Res., 47, W02514, doi:10.1029/2010wr009438, 2011.

Canadian Hydraulic Centre: Green Kenue Reference Manual, National Research Council, 340 pp., Ottawa, Ontario, 2010.

Dibike, Y. B. and Coulibaly, P.: Hydrologic impact of climate change in the Saguenay watershed: comparison of downscaling methods and hydrologic models, J. Hydrol., 307, 145-163, doi:10.1016/j.jhydrol.2004.10.012, 2005.
Emelko, M. B., Silins, U., Bladon, K. D., and Stone, M.: Implications of land disturbance on drinking water treatability in a changing climate: Demonstrating the need for "source water supply and protection" strategies, Water Res., 45, 461-472, doi:10.1016/j.watres.2010.08.051, 2011.

Epstein, D. and Ramírez, J.: Spatial disaggregation for studies of climatic hydrologic sensitivity, J. Hydraul. Eng.-ASCE, 120, 1449-1467, doi:10.1061/(ASCE)07339429(1994)120:12(1449), 1994.

Evans, J. and Schreider, S.: Hydrological impacts of climate change on inflows to Perth, Australia, Climatic Change, 55, 361-393, doi:10.1023/a:1020588416541, 2002.

Forbes, K., Kienzle, S., Coburn, C., Byrne, J., and Rasmussen, J.: Simulating the hydrological response to predicted climate change on a watershed in southern Alberta, Canada, Climatic Change, 105, 555-576, doi:10.1007/s10584-010-9890-x, 2011.

Fowler, H. J. and Kilsby, C. G.: Using regional climate model data to simulate historical and future river flows in northwest England, Climatic Change, 80, 337-367, doi:10.1007/s10584-006-9117-3, 2007.

Fowler, H. J., Blenkinsop, S., and Tebaldi, C.: Linking climate change modelling to impacts studies: recent advances in downscaling techniques for hydrological modelling, Int. J. Climatol., 27, 1547-1578, doi:10.1002/joc.1556, 2007.

Freer, J., Beven, K., and Ambroise, B.: Bayesian Estimation of Uncertainty in Runoff Prediction and the Value of Data: An Application of the GLUE Approach, Water Resour. Res., 32, 2161-2173, doi:10.1029/95WR03723, 1996.

Hamilton, A. S., Hutchinson, D. G., and Moore, R. D.: Estimating winter streamflow using conceptual streamflow model, J. Cold Reg. Eng., 14, 158-175, 2000.

Hamlet, A. F. and Lettenmaier, D. P.: Effects of climate change on hydrololgy and water resources in the Columbia River Basin, J. Am. Water Res. As., 35, 1597-1623, doi:10.1111/j.17521688.1999.tb04240.x, 1999.

Hidalgo, H. G., Das, T., Dettinger, M. D., Cayan, D. R., Pierce, D. W., Barnett, T. P., Bala, G., Mirin, A., Wood, A. W., Bonfils, C., Santer, B. D., and Nozawa, T.: Detection and attribution of streamflow timing changes to climate change in the Western United States, J. Climate, 22, 3838-3855, doi:10.1175/2009jcli2470.1, 2009.

Hughes, J. P., Guttorp, P., and Charles, S. P.: A non-homogeneous hidden Markov model for precipitation occurrence, J. R. Stat. Soc., 48, 15-30, doi:10.1111/1467-9876.00136, 1999.

IPCC: Contribution of Working Groups I, II and III to the Fourth Assessment Report of the Intergovernmental Panel on Climate Change, Core Writing Team, Pachauri, R. K. and Reisinger, A., 104 pp., IPCC, Geneva, Switzerland, 2007.

Jasper, K., Calanca, P., Gyalistras, D., and Fuhrer, J.: Differential impacts of climate change on the hydrology of two alpine river basins, Clim. Res., 26, 113-129, doi:10.3354/cr026113, 2004.

Jha, M., Pan, Z., Takle, E. S., and Gu, R.: Impacts of climate change on streamflow in the Upper Mississippi River Basin: A regional climate model perspective, J. Geophys. Res., 109, D09105, doi:10.1029/2003jd003686, 2004.

Jost, G., Moore, R. D., Menounos, B., and Wheate, R.: Quantifying the contribution of glacier runoff to streamflow in the upper Columbia River Basin, Canada, Hydrol. Earth Syst. Sci., 16, 849-860, doi:10.5194/hess-16-849-2012, 2012. 
Kalogeropoulos, K. and Chalkias, C.: Modelling the impacts of climate change on surface runoff in small Mediterranean catchments: empirical evidence from Greece, Water Environ. J., 27, 505-513, doi:10.1111/j.1747-6593.2012.00369.x, 2013.

Kienzle, S. W., Nemeth, M. W., Byrne, J. M., and MacDonald, R. J.: Simulating the hydrological impacts of climate change in the upper North Saskatchewan River basin, Alberta, Canada, J. Hydrol., 412-413, 76-89, doi:10.1016/j.jhydrol.2011.01.058, 2012.

Lindström, G., Johansson, B., Persson, M., Gardelin, M., and Bergström, S.: Development and test of the distributed HBV-96 hydrological model, J. Hydrol., 201, 272-288, doi:10.1016/S0022-1694(97)00041-3, 1997.

Loukas, A., Vasiliades, L., and Dalezios, N. R.: Potential climate change impacts on flood producing mechanisms in southern British Columbia, Canada using the CGCMA1 simulation results, J. Hydrol., 259, 163-188, doi:10.1016/S00221694(01)00580-7, 2002.

Mahat, V. and Tarboton, D. G.: Canopy radiation transmission for an energy balance snowmelt model, Water Resour. Res., 48, W01534, doi:10.1029/2011wr010438, 2012.

Mahat, V., Tarboton, D. G., and Molotch, N. P.: Testing above- and below-canopy representations of turbulent fluxes in an energy balance snowmelt model, Water Resour. Res., 49, 1107-1122, doi:10.1002/wrcr.20073, 2013.

Maurer, E. P., Adam, J. C., and Wood, A. W.: Climate model based consensus on the hydrologic impacts of climate change to the Rio Lempa basin of Central America, Hydrol. Earth Syst. Sci., 13, 183-194, doi:10.5194/hess-13-183-2009, 2009.

Mebane, W. R. and Sekhon, J. S.: Genetic optimization using derivatives: The rgenoud package for R, J. Stat. Softw., 42, 126, 2011.

Mehrotra, R. and Sharma, A.: Development and application of a multisite rainfall stochastic downscaling framework for climate change impact assessment, Water Resour. Res., 46, W07526, doi:10.1029/2009wr008423, 2010.

Morrison, J., Quick, M. C., and Foreman, M. G. G.: Climate change in the Fraser River watershed: flow and temperature projections, J. Hydrol., 263, 230-244, doi:10.1016/S0022-1694(02)00065-3, 2002.

Mote, P. W.: Trends in snow water equivalent in the Pacific Northwest and their climatic causes, Geophys. Res. Lett., 30, 1601, doi:10.1029/2003g1017258, 2003.

Nash, J. E. and Sutcliffe, J. V.: River flow forecasting through conceptual models, part 1. A discussion of principles, J. Hydrol., 10, 282-290, 1970.

Pierce, D. W., Barnett, T. P., Hidalgo, H. G., Das, T., Bonfils, C., Santer, B. D., Bala, G., Dettinger, M. D., Cayan, D. R., Mirin, A., Wood, A. W., and Nozawa, T.: Attribution of declining Western U.S. snowpack to human effects, J. Climate, 21, 6425-6444, doi:10.1175/2008jcli2405.1, 2008.

Racsko, P., Szeidl, L., and Semenov, M.: A serial approach to local stochastic weather models, Ecol. Model., 57, 27-41, doi:10.1016/0304-3800(91)90053-4, 1991.

Richardson, C. W. and Wright, D. A.: WGEN: A model for generating daily weather variables, A. R. S. US Department of Agriculture, ARS-8, USDA, Washington, DC, 1984.

Richardson, C. W., Barrow, E. M., and Semenov, M. A.: Comparison of the WGEN and LARS-WG stochastic weather generators in diverse climates, Clim. Res., 10, 95-107, 1998.
Seibert, J., McDonnell, J. J., and Woodsmith, R. D.: Effects of wildfire on catchment runoff response: a modelling approach to detect changes in snow-dominated forested catchments, Hydrol. Res., 41, 378-390, doi:10.2166/nh.2010.036, 2010.

Semenov, M. A. and Brooks, R. J.: Spatial interpolation of the LARS-WG stochastic weather generator in Great Britain, Clim. Res., 11, 137-148, 1999.

Silins, U., Stone, M., Emelko, M. B., and Bladon, K. D.: Sediment production following severe wildfire and postfire salvage logging in the Rocky Mountain headwaters of the Oldman River Basin, Alberta, Catena, 79, 189-197, doi:10.1016/j.catena.2009.04.001, 2009.

Stahl, K., Moore, R. D., Shea, J. M., Hutchinson, D., and Cannon, A. J.: Coupled modelling of glacier and streamflow response to future climate scenarios, Water Resour. Res., 44, W02422, doi:10.1029/2007wr005956, 2008.

Stone, M. C., Hotchkiss, R. H., Hubbard, C. M., Fontaine, T. A., Mearns, L. O., and Arnold, J. G.: Impacts of climate change on Missouri River Basin water yield, J. Am. Water Resour. As., 37, 1119-1129, doi:10.1111/j.1752-1688.2001.tb03626.x, 2001.

Toth, B., Pietroniro, A., Conly, F. M., and Kouwen, N.: Modelling climate change impacts in the Peace and Athabasca catchment and delta: I - hydrological model application, Hydrol. Process., 20, 4197-4214, doi:10.1002/hyp.6426, 2006.

Wang, T., Hamann, A., Spittlehouse, D. L., and Aitken, S. N.: Development of scale-free climate data for western Canada for use in resource management, Int. J. Climatol., 26, 383-397, 2006.

Wang, T., Hamann, A., Spittlehouse, D. L., and Murdock, T. Q.: ClimateWNA - high-resolution spatial climate data for Western North America, J. Appl. Meteorol. Clim., 51, 16-29, doi:10.1175/JAMC-D-11-043.1, 2012.

Wilby, R. L., Hay, L. E., Gutowski, W. J., Arritt, R. W., Takle, E. S., Pan, Z., Leavesley, G. H., and Clark, M. P.: Hydrological responses to dynamically and statistically downscaled climate model output, Geophys. Res. Lett., 27, 1199-1202, doi:10.1029/1999g1006078, 2000.

Wilks, D. S.: Stochastic weather generators for climate-change downscaling, part II: multivariable and spatially coherent multisite downscaling, WIREs Clim. Chang., 3, 267-278, doi:10.1002/wcc.167, 2012.

Wood, A. W., Leung, L. R., Sridhar, V., and Lettenmaier, D. P.: Hydrologic implications of dynamical and statistical approaches to downscaling climate model outputs, Climatic Change, 62, 189216, doi:10.1023/B:CLIM.0000013685.99609.9e, 2004.

Zégre, N., Skaugset, A. E., Som, N. A., McDonnell, J. J., and Ganio, L. M.: In lieu of the paired catchment approach: Hydrologic model change detection at the catchment scale,Water Resour. Res., 46, W11544, doi:10.1029/2009WR008601, 2010.

Zhang, L., Dawes, W. R., and Walker, G. R.: Response of mean annual evapotranspiration to vegetation changes at catchment scale, Water Resour. Res., 37, 701-708, doi:10.1029/2000WR900325, 2001.

Zheng, H., Zhang, L., Zhu, R., Liu, C., Sato, Y., and Fukushima, Y.: Responses of streamflow to climate and land surface change in the headwaters of the Yellow River Basin, Water Resour. Res., 45, W00A19, doi:10.1029/2007wr006665, 2009. 